\title{
Adherence to Statin Therapy and Attainment of LDL Cholesterol Goal Among Patients with Type 2 Diabetes and Dyslipidemia
}

This article was published in the following Dove Press journal: Patient Preference and Adherence

\author{
Monira Alwhaibi $\mathbb{D}^{1,2}$ \\ Maha Altoaimi ${ }^{3}$ \\ Yazed AIRuthia (D) 1,4 \\ Abdulkarim M Meraya ${ }^{5,6}$ \\ Bander Balkhi $\mathbb{D}^{1,2}$ \\ Ahmed Aldemerdash ${ }^{1}$ \\ Hadeel Alkofide' \\ Tariq M Alhawassi ${ }^{1,2}$ \\ Abdulmajeed Alqasoumi ${ }^{3}$ \\ Khalid $\mathrm{M} \mathrm{Kamal}^{7}$ \\ 'Department of Clinical Pharmacy, \\ College of Pharmacy, King Saud \\ University, Riyadh, Saudi Arabia; \\ ${ }^{2}$ Medication Safety Research Chair, \\ College of Pharmacy, King Saud \\ University, Riyadh, Saudi Arabia; \\ ${ }^{3}$ Department of Pharmacy Practice, \\ College of Pharmacy, Qassim University, \\ Qassim, Saudi Arabia; \\ ${ }^{4}$ Pharmacoeconomics Research Unit, \\ College of Pharmacy, King Saud \\ University, Riyadh, Saudi Arabia; \\ ${ }^{5}$ Department of Clinical Pharmacy, \\ College of Pharmacy, Jazan University, \\ Jazan, Saudi Arabia; ${ }^{6}$ Pharmacy Practice \\ Research Unit, College of Pharmacy, \\ Jazan University, Jazan, Saudi Arabia; \\ ${ }^{7}$ Division of Pharmaceutical, \\ Administrative and Social Sciences, \\ Duquesne University School of Pharmacy, \\ Pittsburgh, PA, USA
}

Correspondence: Monira Alwhaibi

Department of Clinical Pharmacy, King

Saud University, College of Pharmacy,

Riyadh II I49, Saudi Arabia

Tel +966535384I52

Email malwhaibi@ksu.edu.sa
Background: Statins are widely utilized antidyslipidemics with a proven track record of safety and efficacy. However, the efficacy of these therapeutic agents hinges on patients' adherence to their prescribed statins.

Objective: The primary objectives of this study were to examine the relationship between adherence to prescribed statins and its impact on the low-density lipoprotein (LDL) level, and to explore the factors that influence patient adherence to statins among patients with diabetes and dyslipidemia.

Methods: This was a retrospective, cross-sectional study using the electronic health records data of adults ( $\geq 18$ years) with type 2 diabetes and dyslipidemia visiting outpatient clinics at a university-affiliated tertiary care center. Adherence to statin therapy was estimated using the proportion of days covered (PDC). Patients with diabetes were considered adherent to statins if they had a PDC of $\geq 80 \%$. Treatment success was considered if the LDL level of $<$ $2.6 \mathrm{mmol} / \mathrm{L}$.

Results: Out of 10,226 of patients with diabetes, 1532 met the inclusion criteria and were included in the study. Seventy-nine percent of the patients with diabetes were on atorvastatin and $21 \%$ were on simvastatin. The vast majority of the patients with diabetes $(77 \%)$ were considered adherent and about $42 \%$ achieved LDL-cholesterol goal $<2.6 \mathrm{mmol} / \mathrm{L}$. No association between adherence to statin therapy and LDL goal attainment was observed. Women had lower odds of being adherent to statin therapy ( $\mathrm{AOR}=0.66,95 \%$ CI: $0.49-0.87$ ) compared to men. Further, young adults (18-44 years) had lower odds of being adherent to statin therapy (AOR $=0.58,95 \% \mathrm{CI}: 0.32-0.97$ ) compared to older adults (age $>65$ years).

Conclusion: The findings of this study highlight the need to examine the impact of adherence to statins on healthcare services utilization due to different complications of uncontrolled dyslipidemia.

Keywords: statins, adherence, dyslipidemia, diabetes, low-density lipoprotein cholesterol

\section{Introduction}

Dyslipidemia is a prevalent disorder affecting more than one-third of the adult population ( $\geq 18$ years) in Saudi Arabia ${ }^{1-3}$ putting them at higher risk of coronary heart disease (CHD) and mortality. ${ }^{4}$ Therefore, the National Cholesterol Education Program (NCEP-III) urges health care specialists to start on intensive low-density lipoprotein (LDL) cholesterol reducing program for patients with CHD. ${ }^{5}$ Moreover, the NCEP-III guidelines emphasize the importance of managing dyslipidemia among patients with diabetes since they have a similar risk of experiencing CHD 
events as patients with an established history of CHD. The target LDL level for patients with diabetes is $<2.6 \mathrm{mmol} /$ $\mathrm{L}(100 \mathrm{mg} / \mathrm{dL})$ according to both the NCEP-III and the American Diabetes Association guidelines. ${ }^{6}$

The mainstay of dyslipidemia treatment was and still orally administered antidyslipidemic agents. However, there are multiple classes within this therapeutic group, such as statins which earned top-tier status in the management of dyslipidemia given their proven track record of efficacy and safety compared to other antidyslipidemics. Therefore, it is ranked by the NCEP-III as the first-line treatment for dyslipidemia. ${ }^{5}$ Furthermore, statins are recommended for primary prevention of CHD among adults by the American Heart Association (AHA) guidelines. ${ }^{7}$ This recommendation by the AHA was largely based on generated evidence from multiple randomized clinical trials suggesting a significant reduction in the risk of cardiovascular disease and stroke morbidity and mortality following statin therapy. ${ }^{8-10}$ Thus, intensive treatment of dyslipidemia using statins among highrisk patients such as those with diabetes is warranted.

The clinical effectiveness of statin therapy is contingent upon its ability to significantly reduce the LDL cholesterol level, and failure to reach that goal due to lack of follow-up, inadequate coordination of care, or poor adherence to statin therapy may render these therapeutic agents ineffective. ${ }^{11}$ Therefore, adherence to statin therapy, which was defined as the extent to which patients take their prescribed medication regimens as instructed by their healthcare providers cannot be overemphasized. ${ }^{12}$ Poor adherence to statin therapy can be attributable to multiple reasons such as intolerable side effects, ${ }^{13}$ asymptomatic nature of the disease (e.g. dyslipidemia), high number of medications, ${ }^{14-17}$ socioeconomic status (e.g., age, gender), ${ }^{18,19}$ coexisting chronic health conditions, ${ }^{16,17,19}$ complex treatment regimen, poor patientprovider communication, ${ }^{20}$ and financial constraints. ${ }^{20}$ Hence, ensuring optimal adherence to statin therapy is often challenging as dyslipidemia is an asymptomatic chronic illness and patients sometimes do not recognize the importance of adherence to their statin therapy. This was confirmed in multiple studies. For example, in a prospective cohort study that was conducted among elderly patients taking statins to assess their level of adherence to statin therapy found that only $26 \%$ of the patients with diabetes were adherent to their prescribed statin. ${ }^{21}$ Another study estimated that approximately $50 \%$ of the patients on statins continued their therapy at six months and only $30-40 \%$ at one year. ${ }^{22}$
Adherence to statin therapy is critical to the primary prevention of cardiovascular disease. ${ }^{23}$ Several studies have demonstrated a positive relationship between adherence to statin therapy and LDL goal attainment. ${ }^{1,24,25}$ In a retrospective analysis of 21,239 new statin therapy users, patients who were adherent to their prescribed statins in the first 90 days of statin therapy initiation were more likely to reach their therapeutic goal in lowering the LDL cholesterol levels. ${ }^{24}$ Moreover, another study has investigated the relationship between adherence to statin therapy and lower LDL cholesterol levels among a sample of 653 patients treated for dyslipidemia and found that adherence to statin therapy was significantly higher among patients with a controlled level of LDL. ${ }^{11}$ Similarly, in another retrospective cohort study among 1607 patients using a large employer-based health insurance plan claims data, LDL levels were significantly lower among patients with a Medication Possession Ratio (MPR) of $\geq 80$, which is indicative of adequate adherence, compared to their counterparts with an MPR of $<80 \%{ }^{25}$

Studies that have evaluated patient adherence to statin therapy among patients with diabetes are limited. ${ }^{11}$ Identifying the root causes of poor adherence to statin therapy is important to help identify gaps in the quality of provided healthcare, which can be instrumental in designing individualized interventions aimed at improving adherence to this vital cost-effective class of medications. Therefore, the objective of this study was to examine the association between adherence to statin therapy and LDL cholesterol goal attainment. Further, factors that affect adherence to statin therapy in patients with type 2 diabetes and dyslipidemia were identified.

\section{Methods Study Design}

A retrospective, cross-sectional, electronic health records (EHRs) review study was conducted in a universityaffiliated tertiary hospital in Riyadh, Saudi Arabia. The hospital is one of the largest teaching hospitals in Riyadh, which serves as a referral center for patients primarily from the northern region of Saudi Arabia as well as other regions.

\section{Data Source and Data Extraction}

Data were extracted from the EHRs database for a 12-month period (1st January 2017 to 30th December 2017). The data that were derived from the EHRs include demographics (e.g., age, gender, nationality), clinical data (e.g., LDL 
cholesterol), and clinical diagnosis, which was reported using the clinical diagnosis codes (Appendix I), and prescription drug information (e.g., drug name, dispensing date, quantity dispensed, days of supply and refills).

\section{Ethics Approval and Consent to Participate}

The study was approved by the institutional review board of King Saud University Medical City (IRB\# E-18-3401) and all participants provided informed consent. Patients' identification numbers were encrypted to maintain the confidentiality of the data and stored in password protected and limited accessed computers.

\section{Study Population}

Adults aged $\geq 18$ years, diagnosed with dyslipidemia and type 2 diabetes (using the ICD-10-CM clinical diagnoses codes) from the outpatient setting during a one-year period were included in the study. This study has included only patients who received at least two prescription fills of statin therapy to enable us to calculate the PDC. Patients with missing laboratory observations for LDL cholesterol levels as well as those whose latest LDL cholesterol measurement was within 30 days after the first statin therapy prescription or LDL cholesterol measurement before statin therapy in the EHRs database were excluded.

\section{Measures}

\section{Dependent Variable: Adherence to Statin Therapy}

The proportion of days covered (PDC) was used to measure adherence to statin therapy. Several studies have reported adherence using the PDC measure based on EHRs data and administrative claims data. ${ }^{11,17,18,26}$ PDC was calculated as total days of supply divided by days in the follow-up period (PDC $=$ (total days supply/total number of days evaluated) $\times 100 \%$ ). The date of the first filled statin prescription was considered as the index date. The total days supplied for statin therapy were calculated from the index date till the end of 2017. Patients were considered adherent to statin therapy regimen if their estimated PDC was $\geq 80 \% .{ }^{26}$ Only two statin therapies were identified in this study (i.e., simvastatin, atorvastatin) as they are the only approved formulary medications.

\section{Main Independent Variable: LDL Cholesterol Goal Attainment}

The main independent variable was LDL cholesterol goal attainment which was defined as an LDL level below 2.6 $\mathrm{mmol} / \mathrm{L}(<100 \mathrm{mg} / \mathrm{dl})$ based on the NCEP-III recommendation for patients with diabetes. ${ }^{27}$ This threshold has been reported in the literature to identify LDL cholesterol goal attainment among patients with type 2 diabetes and dyslipidemia. ${ }^{11}$

\section{Other Independent Variables}

Demographics (e.g., age, sex), marital status, chronic health conditions, and polypharmacy were included in the study. Chronic health conditions included hypertension, asthma, osteoarthritis, osteoporosis, anxiety, and depression. These conditions were highly prevalent among patients with type 2 diabetes and dyslipidemia. Polypharmacy was defined as the use of five or more medications ( $\geq 5$ medications). This definition is the most utilized definition of polypharmacy since there is not a consensus on its definition. ${ }^{28-30}$

\section{Statistical Analysis}

Frequencies and percentages were used to describe the categorical variables (gender, marital status, nationality, co-existing chronic conditions, and polypharmacy). Means and standard deviations were used to describe continuous variables (age, adherence, LDL Cholesterol level). Chi-square and Fisher's exact tests were used to examine the factors related to adherence to statin therapy. Multiple regression analysis was conducted to examine the relationship between LDL cholesterol level and adherence to statin therapy controlling for age, sex, marital status, nationality, hypertension, asthma, osteoarthritis, osteoporosis, anxiety, depression, and polypharmacy. All statistical analyses were performed using the Statistical analysis software, version 9.2 (SAS Institute Inc., Cary, NC).

\section{Results \\ Description of the Study Population}

The number of patients who met the inclusion criteria and were included in the study was 1532 . Table 1 displays the characteristics of the study population. The majorities of the study population were women (71\%) and aged 45 to 64 years $(68 \%)$. Hypertension was the most prevalent comorbid health condition among the study sample (68.6\%). Approximately $73 \%$ of the patients with diabetes had polypharmacy ( $\geq 5$ medications).

\section{Adherence to Statin Therapy and LDL Cholesterol Goal Attainment}

Overall, $77.4 \%$ of the patients with type 2 diabetes and dyslipidemia had adequate adherence to statin therapy and 
Table I Characteristics of the Study Population Number and Row Percentage of Characteristics by Statin Adherence Among People with Type 2 Diabetes and Dyslipidemia

\begin{tabular}{|c|c|c|c|c|c|c|c|c|c|}
\hline & \multicolumn{2}{|l|}{ Total } & \multicolumn{2}{|c|}{ Adequate Adherence PDC $\geq 0.8$} & \multicolumn{3}{|c|}{ Poor Adherence PDC $<0.8$} & \multirow[t]{2}{*}{ P-value } & \multirow[t]{2}{*}{ Sig } \\
\hline & $\mathbf{N}$ & $\%$ & $\mathbf{N}$ & $\%$ & $\mathbf{N}$ & $\%$ & Chi-Square Value & & \\
\hline & 1532 & 100.0 & 1186 & 77.4 & 346 & 22.6 & & & \\
\hline Age Mean (SD) & \multicolumn{2}{|c|}{$58.8(10)$} & \multicolumn{2}{|c|}{$58.9(10)$} & \multicolumn{2}{|c|}{$58.0(10)$} & & & \\
\hline LDL Mean (SD) & \multicolumn{2}{|c|}{$2.6(0.89)$} & \multicolumn{2}{|c|}{$2.5(0.8)$} & \multicolumn{2}{|c|}{$2.6(0.9)$} & & & \\
\hline Age Group & & & & & & & 3.81 & 0.28 & \\
\hline 18-44 & 106 & 6.9 & 77 & 72.6 & 29 & 27.4 & & & \\
\hline $45-54$ & 397 & 25.9 & 298 & 75.1 & 99 & 24.9 & & & \\
\hline $55-64$ & 646 & 42.2 & 510 & 78.9 & 136 & 21.1 & & & \\
\hline$\leq 65$ & 383 & 25.0 & 301 & 78.6 & 82 & 21.4 & & & \\
\hline Gender & & & & & & & 14.29 & 0.00 & $* * *$ \\
\hline Men & 443 & 28.9 & 371 & 83.7 & 72 & 16.3 & & & \\
\hline Women & 1089 & 71.1 & 815 & 74.8 & 274 & 25.2 & & & \\
\hline Marital Status & & & & & & & 2.80 & 0.09 & \\
\hline Single & 107 & 7.6 & 90 & 84.1 & 17 & 15.9 & & & \\
\hline Married & 1297 & 92.4 & 1000 & 77.1 & 297 & 22.9 & & & \\
\hline Nationality & & & & & & & 1.59 & 0.21 & \\
\hline Saudi & 1397 & 91.4 & 1076 & 77 & 321 & 23 & & & \\
\hline Non-Saudi & 132 & 8.6 & 108 & 81.8 & 24 & 18.2 & & & \\
\hline Hypertension & & & & & & & 0.70 & 0.40 & \\
\hline Yes & 1051 & 68.6 & 820 & 78 & 231 & 22 & & & \\
\hline No & 481 & 31.4 & 366 & 76.1 & 115 & 23.9 & & & \\
\hline Asthma & & & & & & & 0.65 & 0.42 & \\
\hline Yes & 134 & 8.7 & 100 & 74.6 & 34 & 25.4 & & & \\
\hline No & 1398 & 91.3 & 1086 & 77.7 & 312 & 22.3 & & & \\
\hline Osteoarthritis & & & & & & & 0.32 & 0.57 & \\
\hline Yes & 109 & 7.1 & 82 & 75.2 & 27 & 24.8 & & & \\
\hline No & 1423 & 92.9 & 1104 & 77.6 & 319 & 22.4 & & & \\
\hline Osteoporosis & & & & & & & 0.04 & 0.84 & \\
\hline Yes & 65 & 4.2 & 51 & 78.5 & 14 & 21.5 & & & \\
\hline No & 1467 & 95.8 & 1135 & 77.4 & 332 & 22.6 & & & \\
\hline Anxiety & & & & & & & 3.15 & 0.08 & \\
\hline Yes & 63 & 4.1 & 43 & 68.3 & 20 & 31.7 & & & \\
\hline No & 1469 & 95.9 & 1143 & 77.8 & 326 & 22.2 & & & \\
\hline Depression & & & & & & & 3.98 & 0.05 & $*$ \\
\hline Yes & 29 & 1.9 & 18 & 62.1 & 11 & 37.9 & & & \\
\hline No & 1503 & 98.1 & 1168 & 77.7 & 335 & 22.3 & & & \\
\hline Polypharmacy & & & & & & & 6.08 & 0.02 & $*$ \\
\hline$\geq 5$ & 1116 & 72.8 & 846 & 75.8 & 270 & 24.2 & & & \\
\hline 0 to 4 drugs & 416 & 27.2 & 340 & 81.7 & 76 & 18.3 & & & \\
\hline LDL goal attainment & & & & & & & 0.002 & 0.964 & \\
\hline$<100$ & 636 & 41.5 & 492 & 77.4 & 144 & 22.6 & & & \\
\hline$\geq 100$ & 896 & 58.5 & 694 & 77.5 & 202 & 22.5 & & & \\
\hline
\end{tabular}

Notes: Study population comprised of 1532 People with type 2 diabetes and dyslipidemia (age $\geq 18 y e a r)$ who visited outpatient's clinics from a tertiary hospital. Polypharmacy was defined as the use of five or more medications. Asterisks $\left(^{*}\right)$ represent significant differences in statin adherence from chi-square tests and Fisher's exact tests. $* * * \mathrm{P}<0.001 ; * 0.01 \leq \mathrm{p}<0.05$

Abbreviations: LDL, low density lipoprotein level; PDC, Proportion of Days Covered; SD, Standard Deviation; Sig, Significance. 
$41.5 \%$ of them achieved the LDL cholesterol goal of $<2.6$ $\mathrm{mmol} / \mathrm{L}$ (Table 1). The most frequently prescribed statin therapy was atorvastatin (79.2\%) followed by simvastatin $(20.8 \%)$ (Table 2). The mean LDL cholesterol level was $2.61 \mathrm{mmol} / \mathrm{L}$. The majority of patients with diabetes (77.4\%) who attained LDL cholesterol target had adequate adherence ( $\mathrm{PDC} \geq 80 \%$ ) to statin therapy.

\section{Factors Associated with Adherence to Statin Therapy}

Table 1 also displays the unadjusted associations between independent variables and adherence to statin therapy. No significant association between adherence to statin therapy and LDL cholesterol goal attainment was found, however, adherence to statin therapy significantly differed by gender, depression, and polypharmacy. A significantly higher percentage of patients with diabetes with adequate adherence (PDC $\geq 80 \%$ ) to statin therapy was observed among men compared to women $(83.7 \%$ vs $74.8 \%, \mathrm{P}$ value $=$ 0.0001). Further, the percentage of patients who were adherent to statin therapy was significantly higher among patients without polypharmacy compared to those with polypharmacy $(81.7 \%$ vs. $75.8 \%$, P-value $=0.02)$.

Adjusted odds ratios (AORs) and 95\% confidence intervals (CI) from the multivariable regression analysis on statin adherence are presented in Table 3. Among patients with type 2 diabetes and dyslipidemia, there was an association between adherence to statin therapy and LDL goal attainment. Those who attained LDL cholesterol target did not have higher odds of being adherent to statin therapy compared to those who did not attain LDL cholesterol target $(\mathrm{AOR}=1.27,95 \% \mathrm{CI}$ : 0.97-1.66). Women had lower odds of being adherent to statin therapy (AOR=0.66, 95\% CI: 0.49-0.87) compared to men. Also, young and middle-aged adults (18-44 years) had lower odds of being adherent to statin therapy $(A O R=0.58,95 \%$ CI: $0.32-0.97)$ compared to other age groups ( $\geq 45$ years). Furthermore, those with polypharmacy use had lower odds of being adherent to statin therapy compared to those without $(\mathrm{AOR}=0.67,95 \% \mathrm{CI}: 0.47-0.96)$.

\section{Discussion}

The study estimated the adherence rate to statin therapy among patients with type 2 diabetes and dyslipidemia and identified factors associated with adherence to statin therapy. Around two-thirds of the study population had adequate adherence to statin therapy, which is consistent with the $73 \%$ adherence rate published by Parris et al who also assessed the adherence rate in patients with diabetes and dyslipidemia. ${ }^{11}$ The reported adherence rates in this study are also within the adherence range to statin therapy reported in other studies $(68-80 \%){ }^{25,31}$

Regarding the main independent study variable, $42 \%$ of the study population attained the LDL cholesterol goal. ${ }^{5}$ This finding is consistent with some of the published studies. ${ }^{11,25}$ Parris et al reported that $44 \%$ of adults with diabetes and dyslipidemia achieved their LDL cholesterol goal, ${ }^{11}$ while Wayne et al reported that only $30 \%$ of the patients achieved optimal LDL cholesterol goal. ${ }^{25}$ After adjusting for confounding factors, no association between adherence to statin therapy and LDL cholesterol goal attainment was observed in this study. Published studies have reported that patients who attained LDL cholesterol goal had a higher adherence rate to the statin therapy than those who did not. ${ }^{11,25}$ Another published study has reported no association between adherence to statin therapy and LDL cholesterol goal attainment. ${ }^{19}$ Interestingly, despite the high adherence rate to statin therapy, the level of LDL-C target achievement was low among the study sample. This could be attributable to unmeasured factors such as patients' physical activity and dietary patterns. Unfortunately, these factors were not captured in this study. There is evidence to suggest that nonadherence to statins results in negative health consequences such as higher LDL cholesterol, risk of cardiovascular mortality, hospitalizations, and higher healthcare costs. ${ }^{32}$

Table 2 Statin Therapy, Adherence to Statin Therapy and LDL Cholesterol Goal Attainment

\begin{tabular}{|l|l|l|l|l|l|}
\hline Statin & N (\%) & Mean LDL (mmol/L) & \% Attain LDL goal & Mean PDC (Min, Max) & \% Adherent to Statin PDC \\
\hline All statin & $1532(100.0 \%)$ & 2.61 & 41.51 & $0.88(0.37-1.0)$ & 77.42 \\
Atorvastatin & $1213(79.2 \%)$ & 2.60 & 67.50 & $0.88(0.37-1.0)$ & 76.40 \\
Simvastatin & $319(20.8 \%)$ & 2.64 & 67.70 & $0.89(0.45-1.0)$ & 81.20 \\
\hline
\end{tabular}

Note: Mean PDC range from 0 to I.

Abbreviations: LDL, low density lipoprotein level; PDC, Proportion of Days Covered. 
Table 3 Adjusted Odds Ratios and 95\% Confidence Intervals from Logistic Regression on Adherence to Statin Therapy People with Type 2 Diabetes and Dyslipidemia

\begin{tabular}{|c|c|c|c|c|}
\hline & AOR & $95 \% \mathrm{Cl}$ & $P$ value & Sig. \\
\hline $\begin{array}{l}\text { Age Group } \\
\text { I8-44 } \\
45-54 \\
55-64 \\
>65 \text { (Ref.) }\end{array}$ & $\begin{array}{l}0.56 \\
0.73 \\
0.93\end{array}$ & $\begin{array}{l}{[0.32,0.97]} \\
{[0.49,1.07]} \\
{[0.66,1.32]}\end{array}$ & $\begin{array}{l}0.027 \\
0.083 \\
0.636\end{array}$ & $* * *$ \\
\hline $\begin{array}{l}\text { Gender } \\
\text { Women } \\
\text { Men (Ref.) }\end{array}$ & 0.64 & {$[0.47,0.87]$} & 0.003 & $* *$ \\
\hline $\begin{array}{l}\text { Marital Status } \\
\text { Single } \\
\text { Married (Ref.) }\end{array}$ & 0.56 & {$[0.32,0.98]$} & 0.051 & \\
\hline $\begin{array}{l}\text { Nationality } \\
\text { Non-Saudi } \\
\text { Saudi (Ref.) }\end{array}$ & 0.78 & {$[0.48,1.28]$} & 0.308 & \\
\hline $\begin{array}{l}\text { Hypertension } \\
\text { Yes } \\
\text { No (Ref.) }\end{array}$ & 1.20 & {$[0.89,1.62]$} & 0.138 & \\
\hline $\begin{array}{l}\text { Asthma } \\
\text { Yes } \\
\text { No (Ref.) }\end{array}$ & 0.95 & {$[0.60,1.49]$} & 0.892 & \\
\hline $\begin{array}{l}\text { Osteoarthritis } \\
\text { Yes } \\
\text { No (Ref.) }\end{array}$ & 0.78 & {$[0.48,1.27]$} & 0.307 & \\
\hline $\begin{array}{l}\text { Osteoporosis } \\
\text { Yes } \\
\text { No (Ref.) }\end{array}$ & 1.15 & {$[0.58,2.26]$} & 0.719 & \\
\hline $\begin{array}{l}\text { Anxiety } \\
\text { Yes } \\
\text { No (Ref.) }\end{array}$ & 0.60 & {$[0.33,1.08]$} & 0.114 & \\
\hline $\begin{array}{l}\text { Depression } \\
\text { Yes } \\
\text { No (Ref.) }\end{array}$ & 0.54 & {$[0.23,1.24]$} & 0.155 & \\
\hline $\begin{array}{l}\text { Polypharmacy } \\
\qquad 5 \\
0 \text { to } 4 \text { drugs }\end{array}$ & 0.67 & {$[0.47,0.96]$} & 0.011 & * \\
\hline $\begin{array}{l}\text { LDL goal attainment } \\
\text { Yes } \\
\text { No }\end{array}$ & 1.27 & {$[0.97,1.66]$} & 0.726 & \\
\hline
\end{tabular}

Notes: *Study Population Comprised of 1532 People with type 2 diabetes and dyslipidemia who Visited Outpatient's Clinics from Tertiary Hospital. Asterisks (*) represent significant differences based on statin adherence from logistic regressions with poor adherence as the reference group. ${ }^{* * *} \mathrm{P}<0.00 \mathrm{I} ; * * 0.00 \mathrm{I} \leq \mathrm{p}<0.0 \mathrm{I} ; * 0.0 \mathrm{I} \leq$ $p<0.05$.

Abbreviations: AOR, Adjusted Odds Ratio; $\mathrm{Cl}$, Confidence Interval; Ref, Reference group; Sig, significance.
In this study, men had a significantly higher adherence rate to statin therapy compared to women, which is consistent with other published studies. ${ }^{11,18,19,33}$ Further, young and middle-aged adults had higher adherence rate to statin therapy compared to older age groups something that was noted in previously published studies. ${ }^{18}$ Polypharmacy was also identified as one of the obstacles to adherence to statin therapy. In fact, patients with diabetes are reported to be at a higher risk of being on multiple prescription medications mainly due to diabetes and other comorbid health conditions and at higher risk of drug-drug interaction as compared to non-diabetic counterpart. $^{34,35}$ Polypharmacy among patients with Type II diabetes has been linked to many negative health consequences such as higher risk of all-cause mortality and myocardial infarction as reported by a recent systematic review and meta-analysis study. ${ }^{36}$ Several studies have shown a significant relationship between polypharmacy and poor adherence to statin therapy. ${ }^{14,15}$ Simplifying medication regimens by pharmacists and other healthcare providers should have a positive impact on different health outcomes among patients at high risk of cardiovascular disease such as patients with diabetes and dyslipidemia.

It is important to tackle and manage dyslipidemia in patients with diabetes. Dyslipidemia, as part of the metabolic syndrome, is a cardio metabolic risk factor not only for CHD, but also for other heart diseases, such as atrial fibrillation. ${ }^{37}$ Besides, the use of statins in patients with diabetes can aid in reducing inflammation and oxidative stress levels which also contribute to the pathogenesis of other cardiovascular risk factors such as obesity, diabetes, $\mathrm{CHD} .{ }^{38-40}$

Multiple practical implications can emanate from the present study findings. Adherence to medications depends on the availability of patient counseling and medication therapy management especially among patients with low health literacy level. Therefore, improving the quality of pharmaceutical care is essential to achieve an optimal level of adherence to prescribed drug regimens especially among patients with diabetes. Moreover, public health campaigns to raise public awareness of the importance of adherence to essential medications such as antidyslipidemic agents. In addition, a multidisciplinary policy approach aimed at patients with diabetes, healthcare providers, and healthcare systems should be designed to manage dyslipidemia effectively and prevent major complications. Such policies should entail simplifying treatment regimens, reinforcing and rewarding adherence, encouraging healthcare providers to adhere to treatment 
guidelines, and providing lipid management clinic services. ${ }^{5}$ The study findings suggest that endocrinologists and primary care healthcare providers need to provide routine screening for LDL level, especially for young adults, women, and those who are taking multiple medications. These screenings can detect LDL goal attainment and thus help in improving adherence to statin therapy, thereby preventing the exacerbation of the disease condition and the subsequent negative health consequences. As competing demands to treat multiple conditions may impede the management of LDL cholesterol level, endocrinologists and primary care healthcare providers may need to recognize the non-adherence issue early thereby impacting positive patient outcomes. These should help in the early detection and management of high LDL cholesterol levels as well as in improving adherence to prescribed drug regimens including statins.

Although this study is one of few studies that examined the association between adherence to statin therapy among patients with diabetes and dyslipidemia and LDL cholesterol goal attainment, it has some limitations. The fact that this was a single center study limits the generalizability of its findings. Moreover, the study used the PDC which is a valid and widely used proxy measure for medication adherence, however, it is hard to accurately determine medication adherence using this measure alone since some patients may unintentionally forget or refuse to take their medications due to side effects or other personal reasons. In addition, the causality between adherence to statin therapy and LDL cholesterol goal achievement cannot be established based on the current study design. Finally, multiple covariates have been controlled for in the study; however, some unmeasured confounders such as social factors and patients' beliefs which cannot be captured using EHRs were not controlled for.

\section{Conclusions}

The findings of this study highlight the need to develop different strategies aimed at improving adherence to lifesaving medications such as statins. Future studies should evaluate the impact of long term adherence to statin therapy on the incidence rate cardiovascular diseases and other major complications, healthcare services utilization and costs, and health-related quality of life among patients with diabetes and dyslipidemia.

\section{Acknowledgement}

This research project was supported by a grant from the "Research Center of the Center for Female Scientific and
Medical Colleges", Deanship of Scientific Research, King Saud University.

\section{Disclosure}

Dr Khalid Kamal report grants from Novartis, grants from Johnson and Johnson, outside the submitted work. The authors report no other conflicts of interest in this work.

\section{References}

1. Al-Kaabba AF, Al-Hamdan NA, El Tahir A, Abdalla AM, Saeed AA, Hamza MA. Prevalence and correlates of dyslipidemia among adults in Saudi Arabia: results from a national survey. Open J Endocr Metab Dis. 2012;2:89. doi:10.4236/ojemd.2012.24014

2. Al-Nozha MM, Arafah MR, Al-Maatouq MA, et al. Hyperlipidemia in Saudi Arabia. Saudi Medi J. 2008;29:282-287.

3. Ogbeide DO, Karim A, Al-Khalifa IM, Siddique S. Population based study of serum lipid levels in Al-Kharj Health Center, Saudi Arabia. Saudi Med J. 2004;25:1855-1857.

4. World Health Organization. The World Health Report 2002: Reducing Risks, Promoting Healthy Life. World Health Organization; 2002.

5. Panel on Detection, Evaluation, and Treatment of High Blood Cholesterol in Adults E. Executive summary of the third report of the National Cholesterol Education Program (NCEP) expert panel on detection, evaluation, and treatment of high blood cholesterol in adults (adult treatment panel III). JAMA. 2001;285:2486-2497. doi:10.1001/jama.285.19.2486

6. American Diabetes Association. Standards of medical care in diabetes-2017 abridged for primary care providers. Clin Diabetes. 2017;35:5. doi:10.2337/cd16-0067

7. Graham I, Atar D, Borch-Johnsen K, et al. European guidelines on cardiovascular disease prevention in clinical practice: executive summary: Fourth Joint Task Force of the European Society of Cardiology and Other Societies on Cardiovascular Disease Prevention in Clinical Practice (Constituted by representatives of nine societies and by invited experts). Eur Heart J. 2007;28:2375-2414. doi:10.1093/eurheartj/ehm 316

8. Briel M, Studer M, Glass TR, Bucher HC. Effects of statins on stroke prevention in patients with and without coronary heart disease: a meta-analysis of randomized controlled trials. Am J Med. 2004;117:596-606. doi:10.1016/j.amjmed.2004.04.022

9. Thavendiranathan P, Bagai A, Brookhart MA, Choudhry NK. Primary prevention of cardiovascular diseases with statin therapy: a meta-analysis of randomized controlled trials. Arch Intern Med. 2006;166:2307-2313. doi:10.1001/archinte.166.21.2307

10. McPherson R, Frohlich J, Fodor G, Genest J. Canadian Cardiovascular Society position statement-recommendations for the diagnosis and treatment of dyslipidemia and prevention of cardiovascular disease. Can J Cardiol. 2006;22:913-927. doi:10.1016/S0828282X(06)70310-5

11. Parris ES, Lawrence DB, Mohn LA, Long L. Adherence to statin therapy and LDL cholesterol goal attainment by patients with diabetes and dyslipidemia. Diabetes Care. 2005;28:595-599. doi:10.2337/diacare.28.3.595

12. Osterberg L, Blaschke T. Adherence to medication. $N$ Engl J Med. 2005;353:487-497. doi:10.1056/NEJMra050100

13. Maningat $\mathrm{P}$, Gordon BR, Breslow JL. How do we improve patient compliance and adherence to long-term statin therapy? Curr Atheroscler Rep. 2013;15:291. doi:10.1007/s11883-012-0291-7

14. Jackevicius CA, Mamdani M, Tu JV. Adherence with statin therapy in elderly patients with and without acute coronary syndromes. JAMA. 2002;288:462-467. doi:10.1001/jama.288.4.462 
15. Farsaei S, Sabzghabaee AM, Amini M, Zargarzadeh AH. Adherence to statin therapy in patients with type 2 diabetes: an important dilemma. J Res Med Sci. 2015;20:109.

16. Wawruch M, Zatko D, Wimmer G Jr, et al. Patient-related characteristics associated with non-persistence with statin therapy in elderly patients following an ischemic stroke. Pharmacoepidemiol Drug Saf. 2017;26:201-207. doi:10.1002/pds.v26.2

17. Benner JS, Glynn RJ, Mogun H, Neumann PJ, Weinstein MC, Avorn J. Long-term persistence in use of statin therapy in elderly patients. JAMA. 2002;288(4):455-461. doi:10.1001/jama.288.4.455

18. Juarez DT, Tan C, Davis J, Mau M. Factors affecting sustained medication adherence and its impact on healthcare utilization in patients with diabetes. J Pharm Health Serv Res. 2013;4:89-94. doi:10.1111/jphs.2013.4.issue-2

19. Pittman DG, Chen W, Bowlin SJ, Foody JM. Adherence to statins, subsequent healthcare costs, and cardiovascular hospitalizations. Am J Cardiol. 2011;107:1662-1666. doi:10.1016/j.amjcard.2011.01.052

20. Bates T, Connaughton V, Watts G. Non-adherence to statin therapy: a major challenge for preventive cardiology. Expert Opin Pharmacother. 2009;10:2973-2985. doi:10.1517/14656560903376186

21. Collins R, Armitage J, Parish S, Sleigh P, Peto R. MRC/BHF heart protection study of cholesterol-lowering with simvastatin in 5963 people with diabetes: a randomised placebo-controlled trial. Lancet. 2003;361:2005-2016.

22. Program TRotNCE. Expert panel on detection, evaluation, and treatment of high blood cholesterol in adults (adult treatment panel III) final report. Circulation. 2002;106:3143-3421. doi:10.1161/circ.106. 25.3143

23. Fedder DO, Koro CE, Gilbert J. New National Cholesterol Education Program III guidelines for primary prevention lipid-lowering drug therapy: projected impact on the size, sex, and age distribution of the treatment-eligible population. Circulation. 2002;105:152-156. doi: $10.1161 / \mathrm{hc} 0202.101971$

24. Schultz JS, O’Donnell JC, McDonough KL, Sasane R, Meyer J. Determinants of compliance with statin therapy and low-density lipoprotein cholesterol goal attainment in a managed care population. Am J Manag Care. 2005;11:306-312.

25. Burton WN, Chen C-Y, Schultz AB, Edington DW. The association between achieving low-density lipoprotein cholesterol (LDL-C) goal and statin treatment in an employee population. Popul Health Manag. 2010;13:1-8. doi:10.1089/pop.2009.0020

26. Raebel MA, Schmittdiel J, Karter AJ, Konieczny JL, Steiner JF. Standardizing terminology and definitions of medication adherence and persistence in research employing electronic databases. Med Care. 2013;51:S11. doi:10.1097/MLR.0b013e31829b1d2a

27. Slabaugh SL, Maio V, Templin M, Abouzaid S. Prevalence and risk of polypharmacy among the elderly in an outpatient setting. Drugs Aging. 2010;27:1019-1028. doi:10.2165/11584990-000000000-00000
28. Grimmsmann T, Himmel W. Polypharmacy in primary care practices: an analysis using a large health insurance database. Pharmacoepidemiol Drug Saf. 2009;18:1206-1213. doi:10.1002/pds.v18:12

29. Monégat M, Sermet C, Perronnin M, Rococo E. Polypharmacy: definitions, measurement and stakes involved: review of the literature and measurement tests. Quest D'économie La Santé. 2014;204:1-8.

30. Warren JR, Falster MO, Fox D, Jorm LJP. Factors influencing adherence in long-term use of statins. Pharmacoepidemiol Drug Saf. 2013;22:1298-1307. doi:10.1002/pds.3526

31. Yudin ZM, Yaacob LH, Hassan NB, Ismail SB, Draman N, Yusoff SSM. Achievement of LDL cholesterol goal and adherence to statin by diabetes patients in Kelantan. Malays $\mathrm{J}$ Med Sci. 2017;24:44. doi:10.21315/mjms2017.24.1.12

32. Svensson E, Nielsen RB, Hasvold P, Aarskog P, Thomsen R. Statin prescription patterns, adherence, and attainment of cholesterol treatment goals in routine clinical care: a Danish population-based study. Clin Epidemiol. 2015;7:213. doi:10.2147/CLEP.S78145

33. Donnelly L, Doney A, Morris A, Palmer C, Donnan P. Long-term adherence to statin treatment in diabetes. Diabet Med. 2008;25:850-855. doi:10.1111/dme.2008.25.issue-7

34. Alwhaibi M, Balkhi B, Alhawassi TM, et al. Polypharmacy among patients with diabetes: a cross-sectional retrospective study in a tertiary hospital in Saudi Arabia. BMJ Open. 2018;8:e020852. doi:10.1136/bmjopen-2017-020852

35. Dobrică EC, Găman MA, Cozma MA, Bratu OG, Pantea Stoian A, Diaconu CC. Polypharmacy in type 2 diabetes mellitus: insights from an internal medicine department. Medicina (Kaunas). 2019;55:436. doi: $10.3390 /$ medicina55080436

36. Gaman M, Dobrica E, Pascu E, et al. Cardio metabolic risk factors for atrial fibrillation in type 2 diabetes mellitus: focus on hypertension, metabolic syndrome and obesity. $J$ Mind Med Sci. 2019;6:157-161. doi:10.22543/7674.61.P157161

37. Labib AM, Martins AP, Raposo JF, Torre C. The association between polypharmacy and adverse health consequences in elderly type 2 diabetes mellitus patients; a systematic review and meta-analysis. Diabetes Res Clin Pract. 2019;155:107804.

38. Skalicky J, Muzakova V, Kandar R, Meloun M, Rousar T, Palicka V. Evaluation of oxidative stress and inflammation in obese adults with metabolic syndrome. Clin Chem Lab Med. 2008;46:499-505. doi:10.1515/CCLM.2008.096

39. Lahera V, Goicoechea M, Garcia de Vinuesa S, et al. Endothelial dysfunction, oxidative stress and inflammation in atherosclerosis: beneficial effects of statins. Curr Med Chem. 2007;14:243-248. doi:10.2174/092986707779313381

40. Sørensen AL, Hasselbalch HC, Nielsen CH, Poulsen HE, Ellervik C. Statin treatment, oxidative stress and inflammation in a Danish population. Redox Biol. 2019;21:101088.
Patient Preference and Adherence

\section{Publish your work in this journal}

Patient Preference and Adherence is an international, peer-reviewed, open access journal that focusing on the growing importance of patient preference and adherence throughout the therapeutic continuum. Patient satisfaction, acceptability, quality of life, compliance, persistence and their role in developing new therapeutic modalities and compounds to optimize clinical outcomes for existing disease states are major areas of interest for the journal. This journal has been accepted for indexing on PubMed Central. The manuscript management system is completely online and includes a very quick and fair peer-review system, which is all easy to use. Visit http:// www.dovepress.com/testimonials.php to read real quotes from published authors. 